\title{
Complementary exams in blunt torso trauma. Perform only radiographs and fast: is it safe?
}

\section{Exames complementares na condução do trauma contuso do tronco. É seguro realizar apenas radiografias e fast?}

Fábio Mendes Botelho Filho'; Roberto Carlos de Oliveira e Silva, tCBC-MG'; Sizenando Vieira Starling, tCBC-MG'; Diego Pereira Zillez; Domingos André Fernandes Drumond, TCBC-MG ${ }^{1}$

A B S T R A C T

\begin{abstract}
Objective: to evaluate effectiveness of using chest X-ray (CXR), pelvis X-ray (RXP) and FAST (Focused Abdominal Sonography on Trauma) to exclude significant lesions of the body in blunt trauma. Methods: a prospective study involving 74 patients whom made the three tests (CXR, RXP and FAST) during the initial evaluation between October 2013 and February 2014. The results were compared to the tomography of the same patients or clinical outcome. If the patient did not have alterations on the CT scans or during the observation time, the initial workup was considered safe. All patients were evaluated at the Hospital João XXIII, Belo Horizonte, Brazil. Results: of the 74 patients studied the average age was 33 years, RTS: 6.98, ECG: 12. From 44 (59.45\%) patients with exams (radiographs and FAST) unchanged, three had significant injuries (two splenic injuries and one liver injury) diagnosed by clinical monitoring. The remaining patients - 30 (40.55\%) - had at least one alteration in conventional tests. Of these group 27 (90\%) had significant injuries and three (10\%) minor injuries. The sensitivity of all three tests for screening considerable lesions was $90 \%$ and the specificity was $93 \%$. The negative predictive value was $93 \%$ and the positive predictive value $89 \%$. Conclusion: this research showed that all the three exams - chest X-ray, pelvis and FAST - are safe to lead with the blunt trauma if well used and associated with clinical examination.
\end{abstract}

Key words: Medical Examination. Trauma. Torso. Evaluation. Damage Assessment.

\section{INTRODUCTION}

T rauma is a global disease, being the fifth greatest global cause of death and the first when considering people less than 40 years of age 1 . In Brazil, it represents an even more alarming epidemiological behavior, since it corresponds to the third greatest cause of death and the first when considering the age group 1-44. It accounts for $50.2 \%$ of all deaths from external causesin this age group, and $74 \%$ of deaths in the range $15-24^{2}$. Trauma, therefore, should be seen as a serious public health problem, a disease which requires dedication and experience from the professionals involved. Due to its high prevalence, medical professional experience is essential, even if it is from a field devoid of propaedeutic resources.

In order to evaluate whether minimum research resources are sufficient in relation to tomography, it was decided to investigate the extent to which radiological examinations of primary trauma assessments (pelvic and chest X-rays and FAST - focused abdominal sonography trauma) are sufficient in indicating the best approach for the initial care of polytrauma patients.

\section{METHODS}

Seventy four patients were studied, all blunt trauma victims, and the three exams chest $X$-ray, pelvic $X$-ray and FAST were performed on admission. Data were collected on admission using a protocol developed for this purpose. The data collection period was October 2013 to February 2014 and took place at Hospital João XXIII.

Because there is no specific protocol on image methodology during the initial care at Hospital João XXIII, there was no interference in the surgeon's conduct dealing with each patient. Computed tomography was used selectively as the initial investigation method, according to the cause of injury. The study was based on chart data and examinations, without care intervention, without identification of the patient and therefore with no ethicallegal implications.

To determine whether the request for only three exams (chest X-ray, pelvic X-ray and FAST) would be sufficient for the complementary study of the torso in patients suffering from blunt trauma, two judgment criteria were considered: 1- The initial results of the three exams were

1. Hospital João XXIII, Belo Horizonte - MG - Brasil; 2. Faculdade de Medicina da Universidade Federal de Minas Gerais - MG - Brasil. 
compared to a CT scan of the torso of the same patient; 2 Clinical progress: the patients who did not have a CT scan of the torso during initial examinations were accompanied according to the following protocol: seven days for those who were intubated; 48 hours for those who were conscious but required hospitalization for some other reason (e.g.: orthopedic fracture); 12 hours for those who remained in hospital for only the minimum observation time, according to the standards of the Surgery Department of Hospital João XXIII, in order to present mild trauma, without significant injuries.

\section{RESULTS}

Of the 74 patients studied, their average age was 33, mean (Revised Trauma Score) RTS 6.98 and ECG 12. Of these 74 patients, 44 (59\%) showed unchanged tests (radiography and FAST). However, three patients in this group had significant injuries (two splenic injuries and one liver), diagnosed by another imaging method; computed tomography (CT). The CT scans for these patients were performed within 24 hours after admission, since two of them complained of abdominal pain and the other had a severe tattoo trauma, identified during clinical examination.

The other 30 patients had, in this image set, at least one alteration, for example: free intra-abdominal fluid or rib fracture. Of these 30, 27 patients (90\%) had significant injuries which were diagnosed either by primary examinations (e.g. pelvic fracture identified by pelvic $X$-ray) or by a complementary method (tomography). Significant injuries were defined as those which needed: an evaluation by another expert, a longer observation time and/or an invasive procedure. Only three patients (10\%) had minor injuries, remaining only under hospital observation and were discharged after 12 hours (Table 1).

Therefore, the sensitivity of all three tests for the screening of significant injuries was $90 \%$ and the specificity was $93 \%$. The negative predictive value found was $93 \%$ and a positive predictive value, $89 \%$.

Table 1 - Association of alterations in the set of exams chest X-ray, pelvic X-ray and FAST- with a diagnosis of considerable injuries.

\begin{tabular}{lccc}
\hline Diagnostic & XRF + & XRF - & Total \\
\hline CL+ & 27 & 3 & 30 \\
CL- & 3 & 41 & 44 \\
Total & 30 & 44 & 74 \\
\hline
\end{tabular}

$\mathrm{Cl}+$ considerableinjuries diagnosed; $\mathrm{Cl}$ - no considerableinjuries diagnosed; XRF + alteration in X-rays with FAST; XRF - no alteration in X-rays with FAST.

\section{DISCUSSION}

The study clearly showed that the set of three exams (chest X-ray, pelvis X-ray and FAST) has a sensitivity and specificity of $90 \%$ and $93 \%$ respectively. Therefore its use is recommended when treating blunt trauma to the torso. For those patients who show no alteration in all three exams, and whose clinical examination of the torso is normal, it is inferred that the patient does not have any significant injury within that body segment. Thus, the patient could be referred to another specialist to treat specific injuries or even be discharged early if there are no other associated injuries, according to relevant protocols.

If on the other hand, some of these tests show alterations or the patient has alterations in a clinical examination of the torso, it is necessary for further diagnosis or to pay closer attention, to avoid unnoticed injuries. These findings are consistent with other studies in literature which show the safety of treating patients without tomography scanning as a tracking method ${ }^{3}$.

There are other issues in literature that reinforce the safety of the conduct of cases through conventional studies, leaving the CT as an supplementary examination. Firstly, the effectiveness of the reduction in mortality by way ofa full-body CT scan during initial evaluation remains uncertain in literature ${ }^{4-9}$. There is a lack of important randomized and controlled studies on the subject and there are articles that do not show an associated reduction in mortality ${ }^{4}$. In addition, there is literary support for the use of radiography and ultrasound, since they are validated methods and are used by the most accepted protocols and applied worldwide, in relation to the approach to trauma victims, as defined by ATLS (Advanced Trauma Life Support $)^{9}$. Another important issue to consider is that the use of full-body CT scans during initial assessment does not eliminate the possibility of unnoticed injuries ${ }^{8,10}$. Such an examination has a sensitivity of around $85 \%$, variable in relation to the analyzed region, however its use does not suggest replacement of the well-established diagnostic methods of monitoring and detailed clinical follow-ups ${ }^{4,10}$.

In this study, the group of tests used in the initial evaluation of trauma victims, together with a clinical examination, was able to diagnose any alterations, discarding therefore, any significant torso injury. Of the three "false negative" patients, two had abdominal pain during observation and one had a traumatic abdominal tattoo that suggested a biomechanical high energy trauma, which led to a request for additional tomography.

Another important point of this discussion is the lack of infrastructure in Brazil in relation to the establishment of trauma centers and the large volume of trauma patients attended in Brazilian institutions. In this context, there are strategic benefits to conventional imaging. Among them are reduced costs, fewer skilled professionals and the ease of access to tests in smaller centers, thereby putting them to better use and reducing the burden on major centers. In 
addition, lower doses of radiation should be considered, especially in children and the young. Although there are no Brazilian data on the subject, it is estimated that, in the United States, between 1.5 and $2 \%$ of all diagnosed neoplasms are related to hospital radiation use $\mathrm{e}^{5}$. Such data is relevant to this discussion, since full-body CT scans generate a radiation dose of $10-30 \mathrm{mSv} v^{6,8,11-15}$, which is up to 1,000 times greater than that of a PA chest $X$-ray, whose estimated dose is $0.01 \mathrm{mSv}^{16}$. Thus, a study which can demonstrate the safety of conventional tests, compared to full-body CT scans, can contribute greatly in improving the logistics of referrals to large Brazilian trauma centers ${ }^{17,18}$. Many recent articles describe the benefits of full-body CT scans, however few compare this strategy with conventional imaging, or selective tomography ${ }^{4}$. Thus, little is known about the comparison of these methods and more studies are needed to show that full-body CT is a more effective procedure during the initial evaluation of trauma victims. In this publication, there were no disadvantages apparently with the use of $\mathrm{X}$-rays and fast exams.

Criticisms of this study are based on the lack of homogeneity within the approach in relation to diagnosinga requested image, and the fact that not all patients were examined, which can taint the study. Regarding the lack of homogeneity with the diagnoses, it should benoted that this fault is explained by the extensive knowledge within the institution of the trauma causes. Despite the criticisms, it is clear from above, that the use of pelvic and chest $X$ rays, in addition to FAST and clinical examinations, are still effective tools and must be encouraged in the initial approach to treating trauma patients. In our study, no patient had significant unnoticed injuries, using said methods for an initial evaluation.

It is concluded that CT can be used selectively in cases of altered clinical examinations or when the patient shows alterations in these requested examinations. A full-body CT scan therefore need not be used for an initial diagnosis for all polytrauma patients, which is in tune with Brazilian reality, the reality of a developing country which is seeking to reduce medical costs wherever possible.

This is a pilot study for investigation and the improvement of hospital service. It presents a reliable and applicable option for other Brazilian trauma centers.

\title{
RE S U M O
}

\begin{abstract}
Objetivo: avaliar a efetividade do uso da radiografia de tórax (RxT), pelve (RxP) e FAST (Focused Abdominal Sonography on Trauma) em excluir lesões significativas do tronco no trauma contuso. Métodos: estudo prospectivo envolvendo 74 pacientes no período de outubro de 2013 a fevereiro de 2014 que fizeram, durante a avaliação inicial, os três exames (RxT, RxP e FAST). Os resultados destes exames foram comparados à tomografia de tronco do mesmo paciente ou com a sua evolução clínica com base no tempo de observação protocolado pelo hospital. Todos os pacientes foram atendidos no Hospital João XXIII, Belo Horizonte/MG, Brasil. Resultados: Dos 74 pacientes estudados, a média de idade foi 33 anos, RTS: 6,98, Escala de Coma de Glasgow (ECG): 12. Desses, $44(59,45 \%)$ possuíram os exames (radiografias e FAST) sem alterações, porém três pacientes desse grupo apresentaram lesões importantes (duas lesões esplênicas e uma hepática) suspeitadas através do acompanhamento clínico e definidas pela tomografia posterior. O restante dos pacientes, 30 (40,55\%), tiveram pelo menos uma alteração nos exames convencionais, sendo que, dentro desse grupo, 27 (90\%) apresentaram lesões significativas e três (10\%) lesões leves. A sensibilidade do conjunto dos três exames para triagem de lesões significativas foi $90 \%$ e sua especificidade, 93\%. O valor preditivo negativo encontrado foi $93 \%$ e o valor preditivo positivo, de $89 \%$. Conclusão: O estudo demonstrou que o conjunto dos três exames (radiografia de tórax, pelve e FAST) é seguro para conduzir o trauma contuso do tronco, se for bem utilizado, associado ao exame clínico.
\end{abstract}

Descritores: Exames Médicos. Trauma. Tronco. Avaliação. Avaliação de Danos.

\section{REFERENCES}

1. World Health Organization. WHO. Statute 2014. Acessado em: 11 fev 2015. Disponível em: http://www.who.int/gho/publications/ world_health_statistics/2014/en

2. Brasil. Ministério da Saúde. DATASUS 2012. Acessado em 11 fev 2015. Disponível em: http://www2.datasus.gov.br/DATASUS/ index.php?area $=02$

3. Kendall JL, Kestler AM, Whitaker KT, Adkisson MM, Haukoos JS. Blunt abdominal trauma patients are at very low risk for intraabdominal injury after emergency department observation. West J Emerg Med. 2011;12(4):496-504.

4. Sierink JC, Saltzherr TP, Reitsma JB, Van Delden OM, Luitse JS, Goslings JC. Systematic review and meta-analysis of immediate total-body computed tomography compared with selective radiological imaging of injured patients. Br J Surg. 2012;995uppl $1: 52-8$.

5. Hutter M, Woltmann A, Hierholzer C, Gärtner C, Bühren V, Stengel D. Association between a single-pass whole-body computed tomography policy and survival after blunt major trauma: a retrospective cohort study. Scand J Trauma ResuscEmerg Med. 2011;19:73.

6. Ruchholtz S, Waydhas C, Schroeder T, Piepenbrink K, Kühl H, NastKolb D. The value of computed tomography in the early treatment of seriously injured patients. Chirurg. 2002;73(10):1005-12.

7. Rivas LA, Fishman JE, Múnera F, Bajayo DE. Multislice CT in thoracic trauma. RadiolClin North Am. 2003;41(3):599-616.

8. Asha S, Curtis KA, Grant N, Taylor C, Lo S, Smart R, et al. Comparison of radiation exposure of trauma patients from diagnostic radiology procedures before and after the introduction of a panscan protocol. Emerg Med Australas. 2012;24(1):43-51. 
9. vanVugt R, Kool DR, Deunk J, Edwards MJ. Effects on mortality, treatment, and time management as a result of routine use of total body computed tomography in blunt high-energy trauma patients. J Trauma Acute Care Surg. 2012;72(3):553-9.

10. Stengel D, Ottersbach C, Matthes G, Weigeldt M, Grundei S, Rademacher $\mathrm{G}$, et al. Accuracy of single-pass whole-body computed tomography for detection of injuries in patients with major blunt trauma. CMAJ. 2012;184(8):869-76.

11. Munk RD, Strohm PC, Saueressig U, Zwingmann J, Uhl M, Südkamp NP, et al. Effective dose estimation in whole-body multislice CT in paediatric trauma patients. PediatrRadiol. 2009;39(3):245-52.

12. Tien HC, Tremblay LN, Rizoli SB, Gelberg J, Spencer F, Caldwell $C$, et al. Radiation exposure from diagnostic imaging in severely injured trauma patients. J Trauma. 2007;62(1):151-6.

13. Heyer CM, Rduch G, Kagel T, Lemburg SP, Theisinger A, Bauer $\mathrm{TT}$, et al. Prospective randomized trial of a modified standard multislice CT protocol for the evaluation of multiple trauma patients. Rofo. 2005;177(2):242-9.

14. Wedegärtner $U$, Lorenzen $M$, Nagel HD, Weber C, Adam G. Diagnostic imaging in polytrauma: comparison of radiation exposure from whole-body MSCT and conventional radiography with organspecific CT. Rofo. 2004;176(7):1039-44
15. Brenner DJ, Elliston CD. Estimated radiation risks potentially associated with full-body CT screening. Radiology. 2004;232(3):7358.

16. Brenner DJ, Hall EJ. Computed tomography-an increasing source of radiation exposure. N Engl J Med. 2007;357(22):2277-84.

17. Huber-Wagner S, Lefering R, Qvick LM, Körner M, Kay MV, Pfeifer $\mathrm{KJ}$, et al. Effect of whole-body $\mathrm{CT}$ during trauma resuscitation on survival: a retrospective, multicentre study. Lancet. 2009:373(9673):1455-61.

18. Stengel D, Frank M, Matthes G, Schmucker U, Seifert J, Mutze S, et al. Primary pan-computed tomography for blunt multiple trauma: can the whole be better than its parts? Injury. 2009;40Suppl 4:S36-46.

Received on 05/02/2015

Accepted for publication 02/04/2015

Conflict of interest: none.

Source of funding: none.

Address for correspondence:

Sizenando Vieira Starling

E-mail: sizenando.starling@gmail.com 